\title{
Design of evidence-based gardens and garden therapy for neurodisability in Scandinavia: data from 14 sites
}

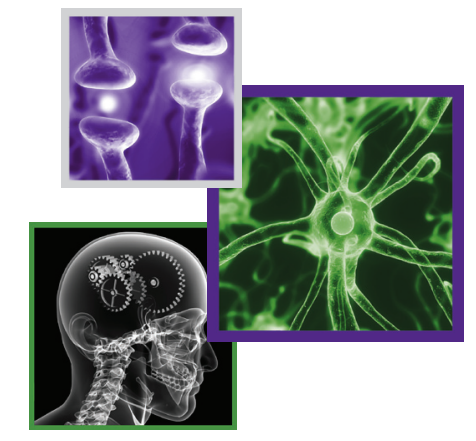

\author{
Josephine Anne Spring*
}

\section{Summary points}

- Gardens are a sensory and stimulating environment for therapy outdoors.

- Healing gardens have been created and assessed for effectiveness in Scandinavia.

- Gardening may increase well being in neurological conditions and dementia clients.

- Scandinavian therapy gardens had simple designs.

- Garden groups in Scandinavia facilitate multidisciplinary therapeutic interventions to encourage movement, communication and cognition and foster therapeutic relationships.

- Evidence was presented on the benefits of indoor plants and views of garden from windows.

- Gardens and gardening groups were assessed with quantitative and qualitative methods and a scale to measure the restorative quality of environments was developed in Scandinavia.

- Scandinavian gardens were compact, simple and flexible in design and growing provided highly visible results which encouraged participation.

- Evidence-based gardens encourage socialization and activity as well as restoration and relaxation.

- Evidence of the therapeutic effects of indoor plants and the views from windows of planting could be considered when new care facilities are planned.

\begin{abstract}
Aim: A total of 14 Scandinavian therapy gardens were visited and data collected on plantings, therapeutic activities and assessment of effectiveness in Spring 2014. Methodology: Data were gathered by a questionnaire and by interviewing staff in Sweden, Denmark and Norway. The data collection structured proforma used the post-occupation assessment method. Results: Gardening promoted physical movement, presented cognitive challenges and provided opportunities for social participation. Half the gardens were enclosed with sensory plants and $85 \%$ were adapted for wheelchairs. A total of $57 \%$ of gardens visited had simple designs with flowers, shrubs, lawns and trees. A social center was important especially for dementia clients. Planted pots were used in $79 \%$ of gardens. The effectiveness of therapy gardens was assessed at $71 \%$ of sites.
\end{abstract}

First draft submitted: 16 October 2015; Accepted for publication: 11 January 2016; Published online: 1 April 2016

In 2011, a study of the suitability of the garden for use by clients with Huntington's disease (HD), relatives and staff, for both therapy and leisure gardening was conducted at the Royal Hospital for Neuro-disability in London [1]. Gardening provided HD clients with a sense of achievement and facilitated activity in a rich sensory environment, involving physical work and cognitive challenges. It also provided choice, self-expression, exposure to nature, ownership in a communal facility and

*Royal Hospital for Neuro-disability, West Hill, Putney, London, SW15 3SW, UK, joseaspring@gmail.com

\section{KEYWORDS}

- adjunct therapy

- dementia • garden

- Huntington's disease

- neurodisability • quality

of life $\bullet$ Scandinavia

Future $\because \%$ Medicine ${ }_{\text {part of }}$ 
material for secondary activities including crafts, cooking, computing and ceramics [2]. Adapted gardening provides an enjoyable leisure activity that achieves visible results in which participants take pride. A recent study of a dementia garden found that the garden increased quality of life for clients [3] and both studies reflect the findings of UK study of Therapeutic Horticulture [4]. The systematic review by York and Wiseman [5] concludes gardening offers meaningful, satisfying opportunities to increase well being, recovery and wider community integration and that of Whear et al. noted [6] reduced levels of agitation in dementia clients. However, therapy gardens often fall into disuse in the UK after being donated at considerable expense. This may be due to a number of factors including: inappropriate design for client use, lack of sustainable planting, requiring too much maintenance, lack of staff knowledge of gardening and complexity with too many features and too little flexible space to accommodate activity.

The Scandinavian countries have specialist Life Sciences Universities which have collaborated with care providers and conducted research into the therapeutic effects of gardens. Research by Stigsdotter and Grahn [7] from Sweden states there are eight characteristics that make a space a healing garden. They are listed in Table 1.

Research has been conducted into therapeutic garden use in Scandinavia which has a similar climate, soil and flora to the UK. The topography of steep slopes and small, flat areas requires design of a compact garden. A research healing garden has been created in Sweden to investigate how well the three schools of thought (healing garden research, horticultural therapy research and instorative experiences) work [8]. Healing gardens influence users in a positive way and promote well being. Horticultural therapy is an activity that is meaningful and enjoyable as well as therapeutic. Instorative experiences can restore a person to a more positive view of self and their capacities. Scientists conducted research on the benefits of landscape viewed from windows [9] and use of indoor plantings [10]. An assessment scale for restorative quality of environments has been tested and verified [11]. Gardens can provide an external environment for other therapies for example, exercise outdoors rather than indoors and environment may affect mood. Investigations led to a design theory for reducing aggression in psychiatric units in Sweden and Denmark [12]. Norway lists green care as one of five national 'Innovation Norway' issues [13] and has 1100 care farms. Benefits for staff and relatives in garden environments have been noted.

Some gardens and rehabilitation facilities with plants have been designed specifically for clients with HD, dementia and acute brain injury in Scandinavia and research conducted on their effectiveness. The Royal Hospital for Neuro-disability wished to extend these benefits to its clients. A Winston Churchill Memorial Fellowship supported travel to Scandinavia.

The aim was to study garden design, garden therapies, assessment methods and evidence of efficacy with a view to incorporate the evidencebased designs and activities on the London site and disseminate the information widely. Due to climatic variation, plantings would have to be adapted to suit local conditions outside the temperate zone.

\section{Methodology}

The post-occupation evaluation research method assesses whether a designed environment delivers to users what the designers intended and was developed by architects. It is used for assessing what therapeutic gardens deliver to users. In health these are: clients, visitors and staff. It was particularly important

\section{Table 1. Characteristics of a healing garden.}

\begin{tabular}{ll}
\hline Characteristic & Definition \\
Serene & A peaceful, silent and caring area \\
Wild & An area facilitating fascination with nature \\
\hline Rich in species & An area offering a variety of species and plants \\
\hline Space & An area facilitating a restful feeling of entering another world, a \\
& coherent whole \\
\hline The common & A green open place allowing vistas and visits \\
Pleasure garden & An enclosed, safe and secluded place \\
Festive & A meeting place for festivity and pleasure \\
Culture/history & A historical place facilitating fascination with the course of time \\
\hline
\end{tabular}


to record how gardens were adapted to include those with significant neurodisability. Also to observe how gardening was conducted to get good results from people with significant and often complex neurodisabilities, which adaptations or techniques worked well and to record these observations. Practical issues needed observation and analysis to inform practice of clinical staff and assist managers with the allocation of scarce resources.

Initial contacts were via a literature search. The sample was defined by those willing to allow a visit, who gardened with those with some form of neurodisability. This is likely to have biased the sample toward those more successful gardens as those in little use or poor maintenance would not want visitors. The Fellow agreed a timetable of visits with hosts in advance of the Fellowship. The length of the visit was defined by the host. Permission to visit was withheld at two sites but all others agreed in advance to a visit during which data would be recorded. The grant was for time limited to 1 month during the growing season (May into June).

\section{- Design}

The data were gathered by a questionnaire and by interviewing staff in Sweden, Denmark and Norway. A structured proforma was developed. The proforma used the post-occupation evaluation method and was drawn up in London based on the work of Heath, the previous London data collection and important design considerations for a garden for those with disability. Each site was photographed to record features and illustrate findings.

\section{- Clients}

The clients attended the sites due to neurological or psychological diagnoses. No photographs of clients were taken for legal reasons.

\section{- Data collection}

The data recorded at each site were:

- Details of design, plantings, garden features and cultivation methods;

- Information on adaptations, therapies and assessments;

- A Likert scale recorded staff ranking importance of activities, benefits and problems associated with gardening.
During the visits experimental literature was presented to the Fellow and this is referred to below.

\section{Results}

\section{- Sites visited}

Fourteen gardens were visited and data collected, Table 2. The data collection was best discussed with hosts but some visits were short and the information had to be drawn from notes and photographs rather than completing the proforma on site with the host. Notes were written up and proformas completed on the day of the visit. The Likert scale was completed by staff at five sites. Discussions were held at two universities on experimental methods to obtain evidence. The sites visited varied widely in character from an inner city roof garden to a therapeutic facility in a stately home in rural surroundings.

\section{- Clinical characteristics}

The clients had a range of neurological and psychiatric diagnoses, some clients having complex, multiple diagnoses. Most sites catered for more than one client group and had a mixture of ambulant and wheelchair-based clients (Figure 1). The length of gardening sessions varied greatly from less than $1 \mathrm{~h}$ to a working day.

Group sizes ranged from five to 15 participants per group. The age ranges catered for at each site were principally adults, nine sites provided services for those aged 35-75 years with ten sites caring for young adults aged 18-35 years and four sites caring for 16-18-year old. Brain injuries are most common in young adults. Only one site took younger children for 1 day per week with an accompanying teacher. Five sites provided services for those over 75 years of age and included dementia care.

\section{- Care provision at participating centers}

Staff numbers related to the size of the center ranging from five to 700 at a hospital site but no volunteers were used. Staff received induction, day release and on the job training as well as attending courses. Ease of recruitment varied with location. Professional staff were recruited from universities or healthcare but apprentices were also employed especially for cultivation and craft activities, with training provided.

\section{- Plantings \& cultivation methods}

The plantings varied but were adapted to local climate, soil and topography. 
Table 2. Sites visited in Scandinavia, garden settings, natural features and age groups of clients.

\begin{tabular}{|c|c|c|c|}
\hline Site visited & Garden setting & Natural features & Age range of clients (years) \\
\hline \multicolumn{4}{|l|}{ Sweden } \\
\hline Garden of Senses, Central Stockholm & Urban garden residential & & $55-75+$ \\
\hline \multirow{2}{*}{$\begin{array}{l}\text { Jordhammars Växtkraft, } \\
\text { Stenungsunds }\end{array}$} & Rural production & Farm & $18-65$ \\
\hline & Horticulture social enterprise & Wildlife haven & \\
\hline Uppsala Botanical Gardens & Urban glasshouse in botanical garden & & $18-35$ \\
\hline \multirow{2}{*}{$\begin{array}{l}\text { Gröna rehab, Göteborg Botanical } \\
\text { Gardens }\end{array}$} & Urban botanical & Forest & $26-63$ \\
\hline & Garden with wilderness & Wildlife haven & \\
\hline \multirow{4}{*}{$\begin{array}{l}\text { Gunnebo Slott, Mölndal near } \\
\text { Göteborg }\end{array}$} & Rural stately home garden & Forest & $18-65$ \\
\hline & & Park & \\
\hline & & Farm & \\
\hline & & Wildlife haven & \\
\hline Dalheimers hus, Göteborg & Urban roof garden residential & & $18-75+$ \\
\hline \multicolumn{4}{|l|}{ Denmark } \\
\hline Tangkær HD Unit, ørsted & Rural garden with glasshouse residential & $\begin{array}{l}\text { Surrounded by woods } \\
\text { and farmland }\end{array}$ & $18-75$ \\
\hline \multicolumn{4}{|l|}{ Norway } \\
\hline $\begin{array}{l}\text { Bjørkas nursing home, Oppegard, near } \\
\text { Oslo }\end{array}$ & Urban residential balcony garden & & $55-75+$ \\
\hline Moer nursing home, Aas & Rural residential garden & & $55-75+$ \\
\hline $\begin{array}{l}\text { Sunaas Rehabilitation Hospital, near } \\
\text { Oslo }\end{array}$ & Rural rehabilitation hospital residential & & $18-75+$ \\
\hline Sand farm, Enebakk kommun & Rural care farm & Farm wildlife haven & Under $18-63$ \\
\hline Røros rehabilitering & Rural rehabilitation center, residential & & Under 18-65 \\
\hline $\begin{array}{l}\text { St Olav's Hospital Neurological Centre, } \\
\text { Trondheim }\end{array}$ & Urban acute hospital residential & & Under $18-75+$ \\
\hline $\begin{array}{l}\text { St Olav's rehabilitation unit, Lian, } \\
\text { Trondheim }\end{array}$ & Rural rehabilitation hospital unit residential & & Under 18-67 \\
\hline
\end{tabular}

Flowers and vegetables were the most popular plants grown and this was reflected in the cultivation type (Figure 2) but floral features and shrubs were used equally as garden features (Figure 3) to draw the eye. Eight sites had lawns and eight had trees, including fruit trees. Other observations noted were: simple garden design, more integration with nature, use of indoor plants in the rehabilitation center and emphasis on the value of viewing nature. There was good plant production with more fruit, less vegetables and more indoor growing than usual in the UK reflecting the more northerly latitudes.

The simplicity of Nordic design focused on plants, although some sites included art installations. The gardens were less built with lawns and paths and had trees for shade, reflecting needs highlighted in Heath's study [14].

\section{Adaptations for cultivation \& access}

Most gardens had adaptations (85\%), most commonly ramps and wider doors to allow wheelchair access. Half the sites were enclosed for privacy.

There were adaptations for growing, pots being the most popular choice $(79 \%)$, having the benefit of portability and ease of planting at a table or a bench which a wheelchair could fit under. The gardens with HD clients were very different settings, in Denmark rural and in Sweden an urban roof garden. However, in both sites the active gardening was in containers. Half the sites had raised beds or planters (Figure 4). Few adapted tools were used but 50\% had sensory plants to stimulate users' senses. The sites visited had varying sensory aspects, colored plantings in Trondheim where there were red, yellow, blue and white themed flowers in soil beds and herbaceous plantings at Sunaas Hospital where culinary herbs were grown. In Göteborg feeling of tree bark was a tactile activity that was novel to the author and the use of a lens to look at microstructures was imaginative. Paraplegic clients had their hands plunged 
into the soil to experience the texture in the roof garden at Dalheimer's Hus in Göteborg.

\section{- Garden-related therapeutic activities}

Gardens are sites of primary production of plant material and may inspire craft activities. In Scandinavia, art and cookery were the most common activities at the sites visited, see Figure 5 . Indeed at the Sunaas rehabilitation hospital in Norway there was a dedicated art room and the clients had designed a special logo for their crafts. In addition, there were three kitchens at this site and more produce was cooked than usual in the UK. In Trondheim, a hemiplegic client cooked waffles for members to eat in the garden at the end of the gardening group. Cooking was a serious activity and groups could be conducted by a professional chef. In most of the residential establishments visited, the chef was considered a part of the therapeutic team and their contribution valued.

There were craft activities including woodwork, concrete sculptures and some mechanical work that may appeal more to men. Jewelry, weaving, wool products, painted stones and bee hive frames were made and sold. Running a stall or shop was part of the therapy. To counter social exclusion and give openings for employment; forestry, grounds maintenance, production horticulture and construction skills were taught. Activities included yoga, dancing, history, photography, pets and cultural, including Viking and Sami, to encourage group participation. Religious holidays were marked more than national holidays.

\section{- Exercise outdoors}

As well as the wide range of crafts associated with the gardening; exercise outdoors was promoted, animal therapy was used - including a physiotherapy dog who was trained to help dementia clients both to move and to socialize. Outdoor exercise was encouraged wherever possible, including in wheelchairs. Sleighs, boats, tricycles and other forms of transport were encouraged. Doing exercises outside was popular. Floor exercises and rest periods were conducted on sheepskins outdoors. In rehabilitation centers, there was emphasis on exercise with well-equipped gyms and swimming pools accessible by ramp and a plastic wheelchair if required.

\section{- Reduction of staff stress}

In Sweden, the use of gardens to reduce staff stress was under investigation at Gröna Rehab in Göteborg [15]. This involved gardening, outdoor exercise, nature study and crafts with therapy sessions.

\section{- Evidence-based gardens}

Of the 14 sites visited, 10 (71\%) were involved in research, 7 (50\%) of which were collaborating with Life Science or other universities. Research was carried out to identify features that will enhance the therapeutic effect of gardens and can be incorporated into the design of new or refurbished gardens. Objective measurements had been made of the restorative effects of gardens to clients using a rating scale and

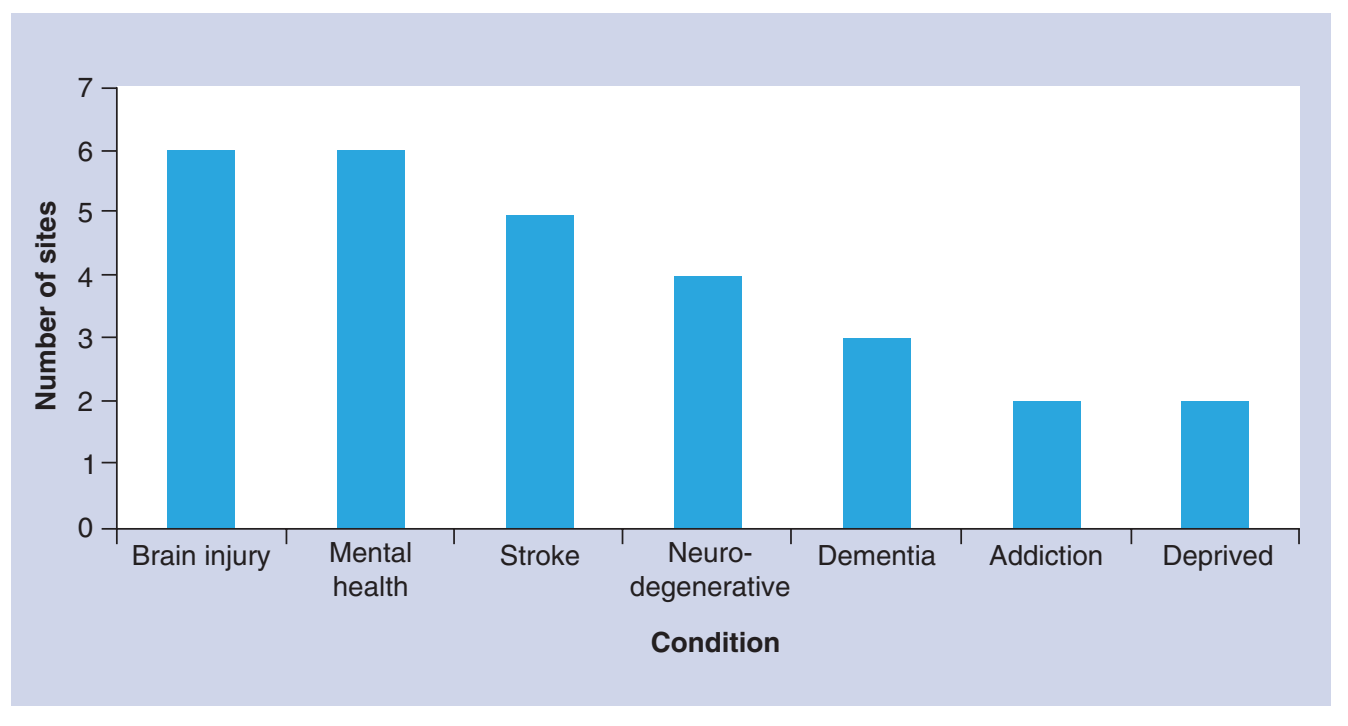

Figure 1. Diagnoses of clients at 14 sites. 


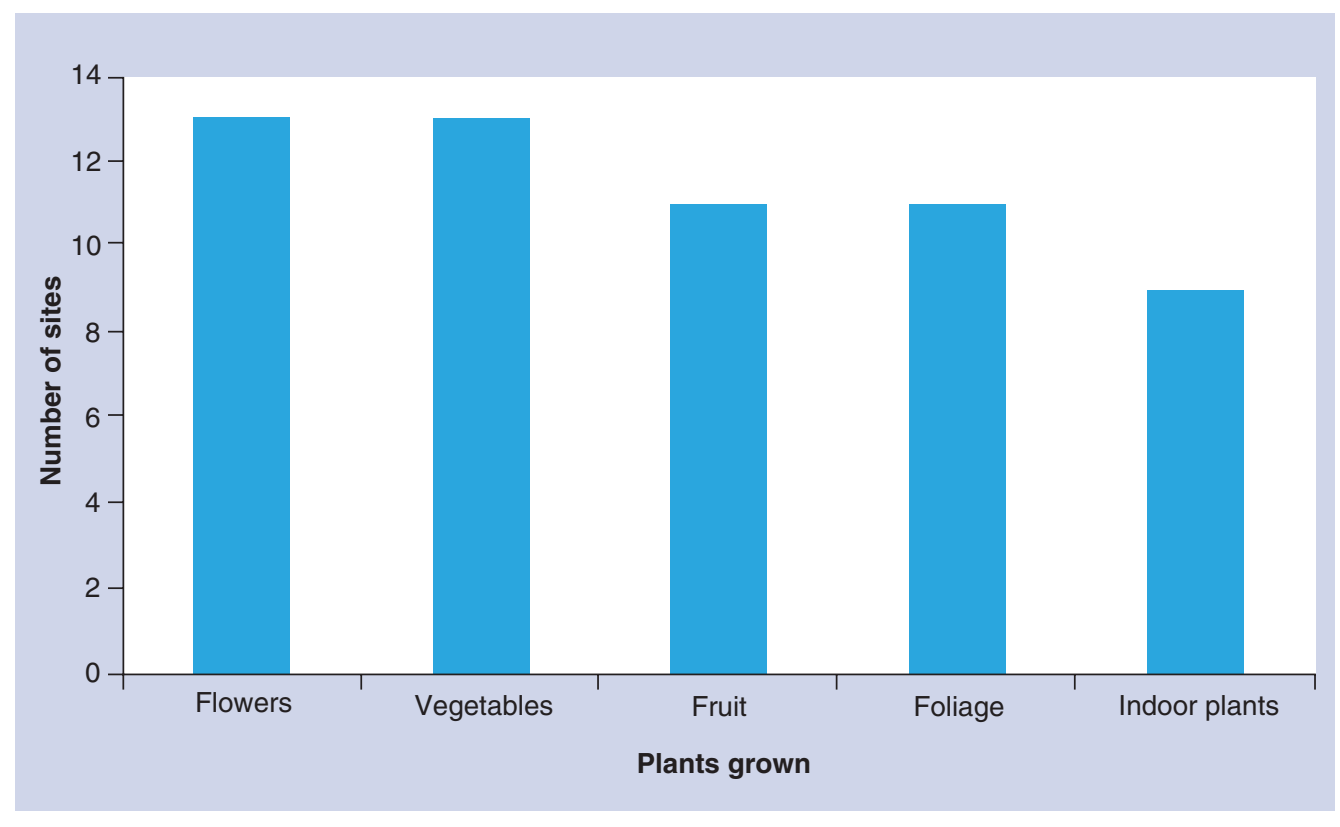

Figure 2. Cultivation of plants at 14 sites.

physiological measurements and of garden therapy programs involving therapy interventions, both horticultural or other therapies conducted outdoors.

\section{- Assessment methods}

Assessment used quantitative and qualitative methods, some assessment scales but also timed interval observations, focus groups and interviews. Assessment scales had been compiled and verified such as the perceived restorative quality of the environment scale of Hartig et al. [11]. Rating scales were used as the principal method at sites with mental health clients. There were a range of measures assessed using rating scales including self-esteem, restoration or collective restoration, impulse control, agitation and problem behaviors. Observations and questionnaires were used in addition at some sites. This contrasted with elderly care sites that used observations and reports. Rehabilitation units used a wider range of measures, particularly rating scales such as Functional Independence Measure with Multi Disciplinery Team reports, and questionnaires, observations, interviews or focus groups. Physiological measures including blood pressure and heart rate [16] were recorded in experiments at the Røros rehabilitation center. The sites providing vocational rehabilitation used observation with reports or interviews and in one case a questionnaire. Garden features that help families to cope better with stress need investigation and this had not been investigated at the sites visited. The pictorial questionnaire and post-occupation assessment methods used in London were of interest to the Scandinavians [1].

\section{- Research examples from Scandinavia}

Useful studies include the work on design of gardens for dementia which gives a framework for the design of gardens in residential care sites with ten features [17]. It was supported by the Competence Centre for Ageing and Health, Norwegian Royal Horticultural Society (Hagenselkap) and the National Bank (Husbanken) and a book written which has been translated into English [17]. Eight pilot gardens were examined for design features that would assist dementia clients. This led to the following features being recognized as important: green, secure, paths, seats, social center, popular plants, activities, cultural or historical links, water and a pleasing view. This has been augmented by a review of garden and horticultural activities in dementia [18]. The Oslo botanical garden has a sensory garden with plants from a century ago that provides a useful reference collection for plant choice and is an excellent display [19].

The work at Gröna Rehab, on getting stressed healthcare staff back to work and preventing staff getting stressed, was strictly evidence based and under assessment using rating scales, questionnaires and participant 
interviews following a cohort of predominantly female clients who may have been on sick leave for between 3 months and 12 years. They had been diagnosed with moderate to severe depression and stress. After a 3 month intervention $93 \%$ return to work or study and after 18 months $86 \%$ are still in work or study [20]. Decreased stress for staff and relatives in a dementia therapy garden has been reported in the UK study by Edwards et al. [3].

The research at Røros [9,10] on indoor plants assisting with rehabilitation used questionnaires that sought information on self-reported mental and physical health SF-12 and affect circumflex. Nine of the 14 sites visited had indoor growing. The views from the rehabilitation center were assessed using the perceived restorativeness scale that tests fascination, attention, restoration and stress [21] for identifying potential in promoting recovery. All 14 sites had views of the garden from the windows, six had pictures of plants and nature and two used computers to view aspects of these.

If projects have been assessed, the evidence can then be put to a wider group of those involved with the design of healthcare facilities. This would include senior management, estates workers, think tanks, architects, engineers, builders and planners (Figure 6) [22].

\section{- Therapeutic benefits \& challenges}

Staff completed the Likert scale at five sites. All agreed gardening provided physical, psychological and social benefits. Important horticultural activities were: propagation, harvesting and viewing nature, with associated art and cookery. There was less consensus on garden-related activities except for art and cooking; a majority thought music in the garden unimportant. Four sites felt the gardening groups helped teach life skills. An occupational therapist stated "You get highly visible results; it provides an opportunity for staff and therapists to relate to patients. It provides good opportunities for cognitive and physical therapy."

Problems identified were related to participants getting too hot or cold and tired. However, fatigue may be a feature of neurodegenerative disease and brain injury. Only one incident related to sharp tools was reported. No one in Scandinavia thought that getting dirty was a problem in contrast to the study in London.

Funding was considered difficult to obtain by the majority but most sourced funding from regional or national government or the health provider. Few sourced funding from charity or commerce, see Figure 7. Some sites received funding from more than one source, Sand Care farm received national and local funding, Dalheimer's Hus from local government and the health funder, the Rehabilitation Center at Røros is funded by a charity in addition to the health provider and Jordhammars Växtkraft from national and local government, health and commerce. This diversification of funding may help sustain the therapeutic activities (Figure 7).

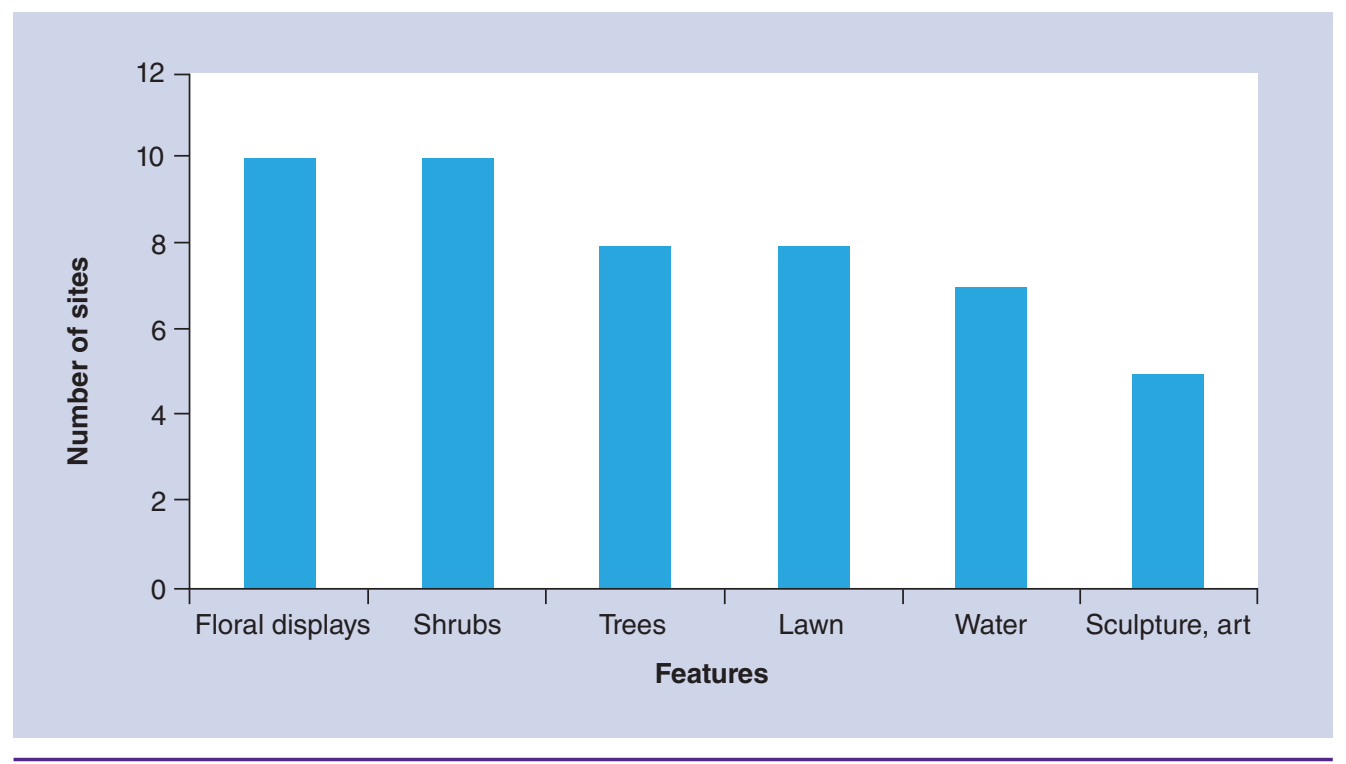

Figure 3. Garden design features at 14 sites. 


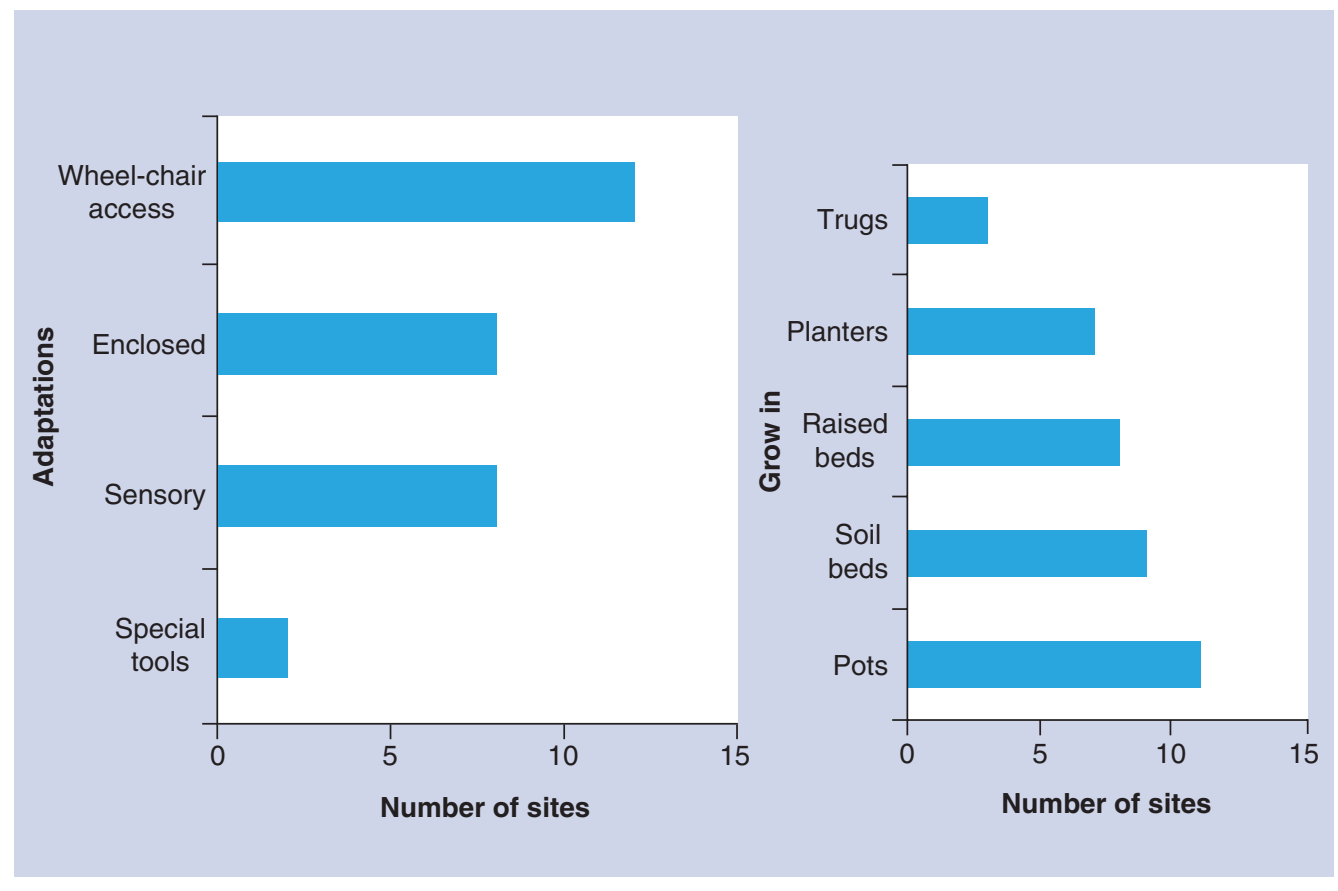

Figure 4. Growing methods and adaptations at 14 sites.

\section{Discussion}

- Limitations on the data collection

Appointments were booked in advance and some hosts had limitations on the time available for visitors. Some data were discussed more fully with hosts on site, other data were gathered from notes taken during the visit, information presented and photographs but collated the same day. Due to time constraints, the Likert scale was only completed at five sites.

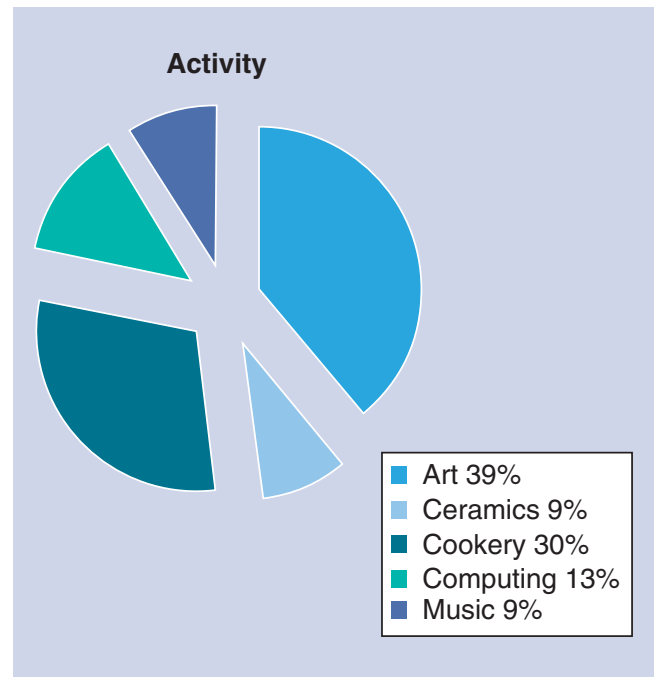

Figure 5. Most common activities related to gardening at 14 sites.
The aspect most valued by the hosts was mapping activity in Scandinavia which has been acknowledged as helpful on the Fellow's return. With hindsight a more consistent data collection would have been obtained if each visit was for over half a day.

\section{- What are the characteristics that make a garden therapeutic?}

Research by Stigsdotter and Grahn [7] states there are eight characteristics that make a space a healing garden (see Table 1). This model has some contradictions, for example, between an open or enclosed area and there is more emphasis on passive interaction with nature and gardens to promote relaxation reflecting the healing garden and instorative experiences. Berentsen et al. [17] suggest some common features with Stigsdotter and Grahn [7] such as green, secure and historical or cultural links but contrasts this with more active therapeutic use of the garden as a social, activity and reminiscence facility with popular plants that are pleasing to the eye.

\section{- Design}

Gardens in Scandinavia were simple in design and less built than those described by Davis [23] in the USA and Heath [14] in Canada. Post-occupation assessments showed 


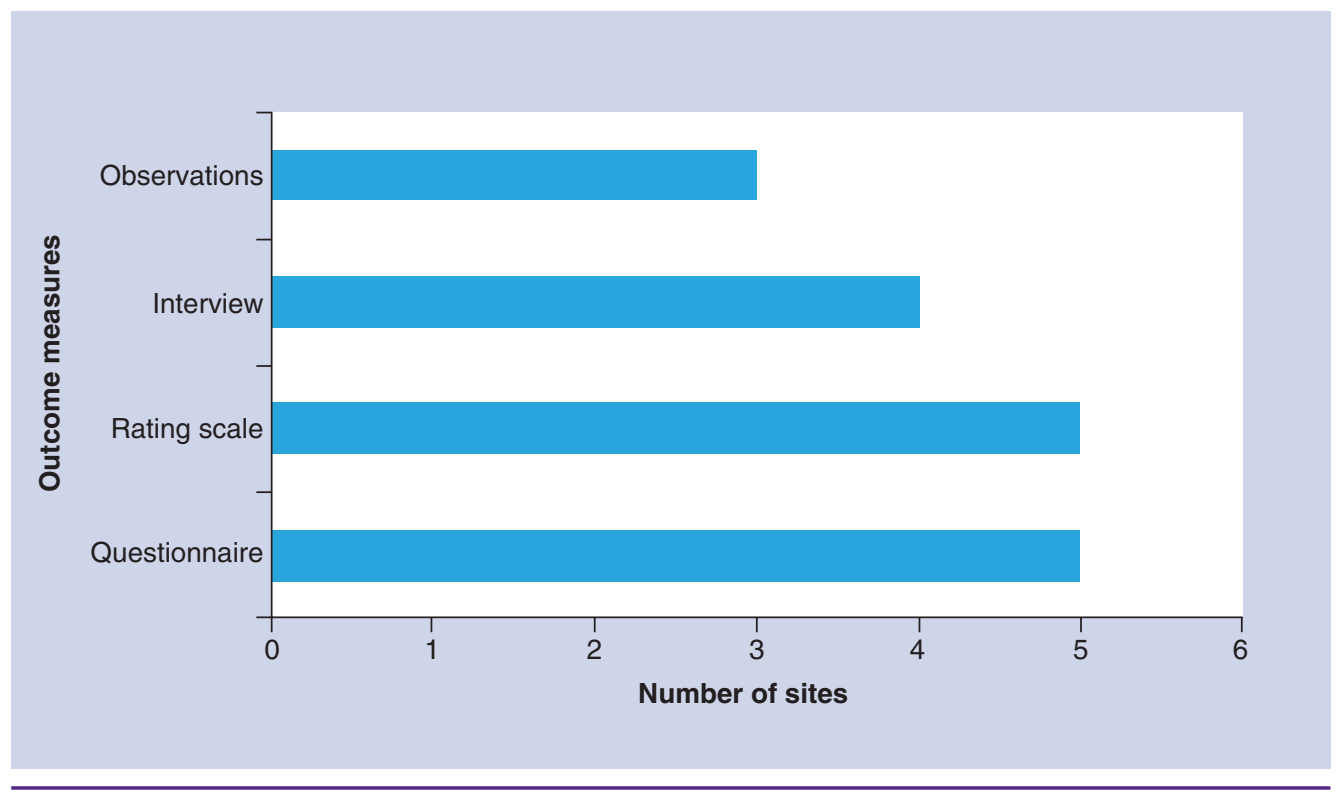

Figure 6. Outcome measures used.

low accessibility, poor maintenance, lack of staff availability in America and in Canada garden users felt access was difficult and the environment of paving, brick raised beds where clients could not garden and handrails too 'busy' with insufficient shade. A client had climbed into a water feature. The users requested a simple open space with a lawn. The majority of Scandinavian gardens contained lawns, soil level beds, trees for shade $(57 \%)$ as well as practical raised beds which facilitated wheelchair-based clients gardening. A social center with seating was surrounded by popular plants. Water features were robust stones with water trickling over them. Dementia clients may benefit from a well-planned garden with a social center and activities. This assisted sleep pattern, affect and well being and may reduce the use of psychotropic drugs and serious falls $[18,24,25]$. Small gardens not cluttered with features provided a flexible space for activities and cultivation was in inexpensive pots, planters or wooden containers.

\section{- Contrasts between countries}

Only one site was visited in Denmark for HD clients in a rural setting which contrasted to the urban roof garden for this client group in Sweden. However, in both sites the active gardening was in containers. There was more emphasis in the Swedish gardens on stress reduction for both clients and health service workers compared with the seven Norwegian gardens where activity outdoors was encouraged and much thought was given to facilitating as many people as possible to participate in this. When the weather is bad, outdoor activity continued in snow on sledges, cultivation being re-directed to indoor plants and crafts. Sensory gardening in Scandinavia had a different emphasis to that of the London garden. In London, tall plants are used to attract the eye by movement as well as color, soft leaves to encourage touching rather than rough bark, red is attractive for one client group so is dominant, scented plants used as olfactory stimulus more than culinary use. Fresh strawberries are used as a reward at the end of sessions or to mark progress if swallowing ability permits.

\section{- Group participation}

Participation in a therapy group requires practical considerations such as how participants may access the garden, including in wheelchairs. How many people attend the group and the balance between clients and staff needs thought. Facility size, ownership, management and staff to client ratio consistently influence staff ability to give quality care [26]. Staff experienced working with clients on ergonomic approaches to enable gardening are useful [1]. Space may facilitate activity more than a busy environment. In Scandinavia, contact between clients and the therapy staff from a wide range of disciplines happens in the garden and there was often a mix of therapists present. 


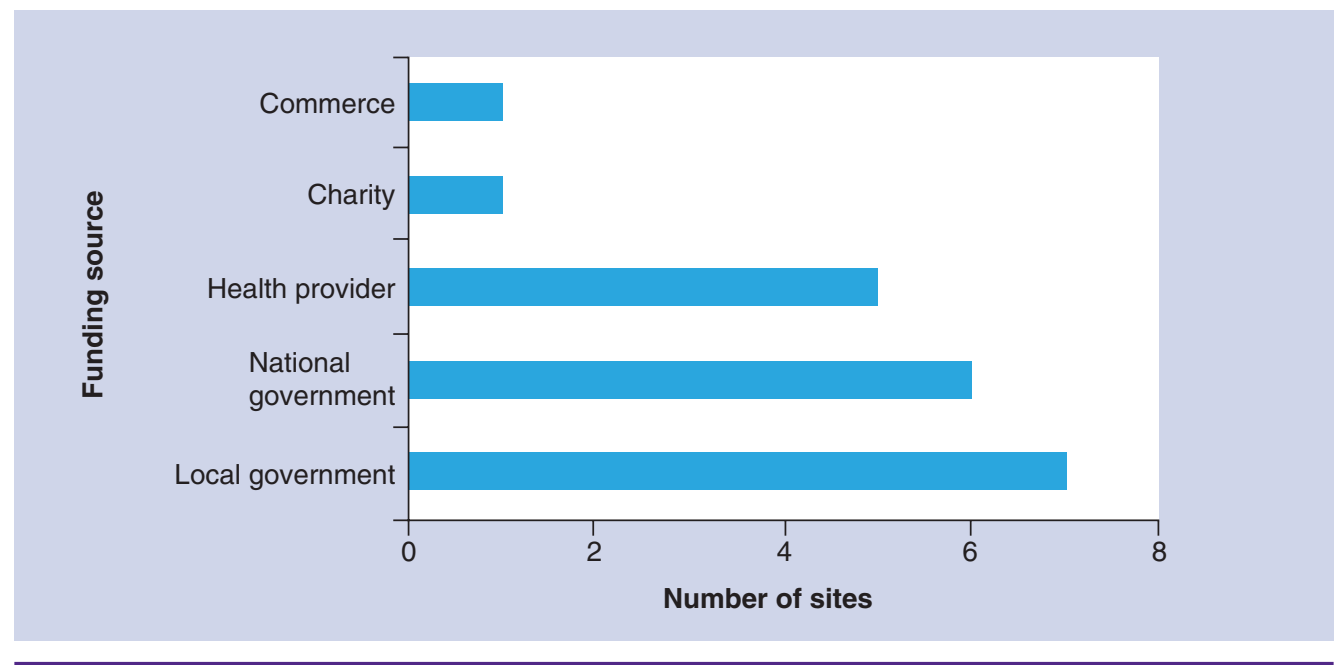

Figure 7. Funding sources.

Different disciplines may pose different therapy challenges to clients, ranging from physical movements to sequencing, choice and speech. Working alongside the clients really acquaints the staff with them. Gardening is productive and engages participants in sensory and creative processes with visible end products, this activity is beneficial, adds to quality of life and resident relationships [27] is voluntary and may be complicated [28]. The group may do related activities such as cookery. In addition, there was an emphasis on physical activity outdoors, especially in Norway, Rehabilitation for social exclusion included instruction in vocational activities where there were openings for employment [29].

\section{- Therapeutic indoor plants \& vistas from windows}

Raanaas et al. [10] presented data on the beneficial effects of indoor plants based on their use in a rehabilitation facility. A moderate positive response was recorded when indoor plants were introduced, more noticeable in women than men. Women reported better physical health after the intervention, also noted by Grinde and Patil [30]. This evidence is reviewed critically by Bringslimark, Hartig and Patil [31] who supported the view that pain management is enhanced by the presence of indoor plants. A further study measured the effects of views from windows in Norway [9] using the restorative quality of environments scale of Hartig et al. [11]. Views of the forest had higher scores than those of the town and the buildings. So the potential view from windows, especially from bedrooms and dayrooms should be included in planning buildings, gardens and landscapes in care establishments [22].

\section{- Staff \& family stress}

Caring for clients with neurodisability or mental health issues may be stressful, especially over a long period. The research in Göteborg on how to rehabilitate stressed staff so they return to work in the health service is very innovative but strictly evidence-based and illustrates how gardens, nature and therapy can help rehabilitate staff, [20] and gardens may reduce stress in staff and family members [3].

\section{Conclusion}

Gardens provide a sensory and creative environment for therapy. The gardens were compact, simple and flexible in design. The majority had lawns, soil level and raised beds, trees for shade and a social center. This model may facilitate therapy; encourage socialization and activity as well as restoration and relaxation. The gardens were not cluttered with built features. Gardening is used to promote physical movement, present cognitive challenges and provide opportunities for social participation including with staff. It has highly visible outputs. Indoor plants and the views from windows of planting are also therapeutic in a passive way and should be considered when new facilities are planned. Due to a similar climate, flora and geology, simple gardens and therapeutic activities could be replicated in the UK and, with plantings suited to the climate and soil, elsewhere in the world. 


\section{Future perspective}

The environment can have a positive influence on quality of life for those with neurodegenerative conditions. Evidence can be applied in the design or upgrading of care facilities to provide small garden areas. Therapy and leisure activities in the garden should be considered as a part of care as client gardening produces visible results that may be viewed with pride. Common flowers or shrubs in an inexpensive planter can enhance the view from a window and indoor plants improve the experience of care by clients. Simple gardens with space for social and therapeutic activity should be a standard consideration for care facilities as these can host multiple therapies and provide contact with nature.

Post-occupation assessment of gardens and indoor plantings are necessary to highlight benefits and problems at each site.

\section{Acknowledgements}

J Spring thanks the Scandinavian hosts, S Duport, Royal Hospital for Neuro-disability, S Turner, Trauma Clinic and $G$ Hyde, London in Bloom.

\section{Financial \& competing interests disclosure}

This work was supported by the Winston Churchill Memorial Trust grant number F-1026699, 2014. The author has no other relevant affiliations or financial involvement with any organization or entity with a financial interest in or financial conflict with the subject matter or materials discussed in the manuscript apart from those disclosed.

No writing assistance was utilized in the production of this manuscript.

\section{Ethical conduct of research}

The authors state that they have obtained appropriate institutional review board approval or have followed the principles outlined in the Declaration of Helsinki for all human or animal experimental investigations. In addition, for investigations involving human subjects, informed consent has been obtained from the participants involved.

\section{Open access}

This work is licensed under the AttributionNonCommercial-NoDerivatives 4.0 Unported License. To view a copy of this license, visit http://creativecommons.org/ licenses/by-nc-nd/4.0/

\section{References}

Papers of special note have been highlighted as:

- of interest; $\bullet \bullet$ of special interest

1 Spring J, Viera M, Bowen C, Marsh N. Is gardening a stimulating activity for people with advanced Huntington's disease? Dementia 13(6), 819-833 (2014).

2 Spring JA, Baker M, Dauya L et al. Gardening with Huntington's disease clients - creating a programme of winter activities. Disabil. Rehabil. 33(2), 159-164 (2011).

3 Edwards CA, McDonnell C, Merl H. An evaluation of a therapeutic garden's influence on the quality of life of aged care residents with dementia, Dementia 12(4), 494-510 (2013).

- Shows benefits on quality of life in a care home.

4 Sempik J, Aldridge J, Becker S. Health, Well-being and Social Inclusion, Therapeutic Horticulture in the UK. Bristol: The Policy Press, England, 1-12 (2005).

5 York M, Wiseman T. Gardening as an occupation: a critical review. Br. J. Occup. Ther. 75, 76-84 (2012).

6 Whear R, Coon JT, Bethel A, Abbott R, Stein $\mathrm{K}$, Garside R. What is the impact of using outdoor spaces such as gardens on the physical and mental well-being of those with dementia? A systematic review of quantitative and qualitative evidence. J. Am. Med. Dir. Assoc. 15(10), 697-705 (2014).

7 Stigsdotter UA, Grahn P. 'What makes a garden a healing garden?' J. Ther. Horticulture 13, 60-69 (2002).

- Explains elements contributing to a therapeutic garden.

8 Stigsdotter UA, Grahn P. Experiencing a garden: a healing garden for people suffering from burnout diseases. J. Ther. Horticulture 14, 38-48 (2003).

9 Raanaas RK, Patil GG, Hartig T. Benefits of a view of nature for patients in a residential rehabilitation center. Clin. Rehabil. 25(1), 21-32 (2012).

10 Raanaas RK, Patil GG, Hartig T. Effects of an indoor plant intervention on patient well-being during a residential rehabilitation program. Hort. Sci. 45(3), 1-6 (2010).

11 Hartig T, Korpela GW, Evans GW, Gärling T. A measure of restorative quality in environments. Scandinavian Hous. \& Plann. Res. 14, 175-194 (1997).

-• Measure of the restorative quality of environments.

12 Ulrich RS, Bogren L, Lundin S. Toward a design theory for reducing aggression in psychiatric facilities. ARCH 12 12, 12-14 (2012).

13 Norwegian Ministry of Agriculture and Food with Norwegian Ministry of Local

Government, Green Care a National Strategy, Oslo, Norway (2012). www.regjeringen.no/globalassets

14 Heath Y, Evaluating the effect of therapeutic gardens. Am. J. Alzheimers Dis. Other. Demen. 19, 239-242 (2004).

15 Larsson E. Gröna Rehab. Vastra Götalandsregionen, Göteborgs Botaniska Trädgård, Göteborg, Sweden (2010).

16 Hartig T, Evans GW, Jamner LD, Davis DS, Gärling T. Tracking restoration in natural and urban field settings. J. Environ. Psychol. 23, 109-123 (2003).

17 Berentsen VD, Grefsrød E-E, Eek A. Gardens for people with dementia, Forlaget aldringog Helse, Oslo, Norway (2008).

18 Gonzales MT, Kirkevold M. Benefits of sensory garden and horticultural activities in dementia care: a modified scoping review. Clin. Nurs. 19, 2698-2715 (2013).

19 Borgen L, Guldhal AS. Great-granny's garden: a living archive and a sensory garden. Biodivers. Conserv. 20, 441-449 (2011).

- Lists a wide selection of popular plants for reminiscence gardening. 
20 Sahlin E, Ahlborg G Jr, Matuszczyk JV, Grahn P. Nature-based stress management course for individuals at risk of adverse health effects from work-related stress - effects on stress related symptoms, workability and sick leave. Int. J. Environ. Res. Public Health. 11(6), 6568-6611 (2014).

21 Laumann K, Gärling T, Stormark KM. Rating scale measures of restorative components of environments. J. Environ. Psychol. 21, 31-44 (2001).

22 Hartig T, Bringslimark T, Patil GG. Restorative environmental design: what, when, where, and for whom? In: Bringing Building to Life: The Theory and Practice of Biophilic Building Design. Kellert S, Heerwagen J, Mador M (Eds). John Wiley $\&$ Sons, New York, USA (2008).

23 Davis BE. Rooftop hospital gardens for physical therapy: a post occupancy evaluation. HERD 4(3), 14-43 (2011).
- Method for evaluating garden space usage.

24 Detweiler MB, Sharma T, Detweiler JG et al. What is the evidence to support the use of therapeutic gardens for the elderly? Psychiatry Investig. 9(2), 100-110 (2012).

25 Detweiler MB, Murphy PF, Kim KY, Myers LC, Ashai A. Scheduled medications and falls in dementia patients utilizing a wander garden, Am. J. Alzheimers Dis. Other Demen. 24(4), 322-332 (2009).

26 Chenoweth L. Long-term care characteristics that influence the utility and effectiveness of nonpharmacological therapies for people with dementia. Neurodegener. Dis. Manag. 5(2), 109-119 (2015).

- Discusses management issues that affect nonpharmacological interventions in care settings.
27 Raske M. Nursing home quality of life: study of an enabling garden. J. Gerontol. Soc. Work. 53(4), 336-351 (2010).

28 Jonasson I, Markland B, Hildingh C. Working in a training garden: experiences of patients with neurological damage. Aust. Occup. Ther. J. 54, 266-272 (2007).

29 Mulder R, 6 år med Jordhammars Växtkraft, Stenungsunds kommun (2013). www.stenungsund.se/download

30 Grinde B, Patil GG. Biophila: does visual contact with nature impact on health and well-being? Int. J. Environ. Res. Public Health 6(9), 2332-2343 (2009).

31 Bringslimark T, Hartig T, Patil GG. Psychological benefits of indoor plants - a critical review. J. Environ. Psychol. 29, 422-433, (2009). 